\title{
Correction to: Temporal emergence of age-associated changes in cognitive and physical function in vervets (Chlorocebus aethiops sabaeus)
}

\author{
Brett M. Frye (D) Payton M. Valure $\cdot$ Suzanne Craft $\cdot$ Mark G. Baxter $\cdot$ Christie Scott $\cdot$ \\ Shanna Wise-Walden · David W. Bissinger · Hannah M. Register · Carson Copeland • \\ Matthew J. Jorgensen · Jamie N. Justice • Stephen B. Kritchevsky • Thomas C. Register • \\ Carol A. Shively (D)
}

Published online: 12 August 2021

(C) American Aging Association 2021

\author{
Erratum to: GeroScience (2021) 43:1303-1315 \\ https://doi.org/10.1007/s11357-021-00338-w
}

The original version of this article unfortunately contained an error in the funding section. One of the grant was omitted in the published paper and the corrected funding statement was given below.

The original articles can be found online at https://doi.org/ 10.1007/s11357-021-00338-w.

B. M. Frye · P. M. Valure · C. Scott · S. Wise-Walden ·

D. W. Bissinger · H. M. Register · C. Copeland ·

M. J. Jorgensen · T. C. Register · C. A. Shively $(\bowtie)$

Department of Pathology - Comparative Medicine,

Wake Forest School of Medicine, Medical Center Blvd,

Winston-Salem, NC 27157-1040, USA

e-mail: cshively@wakehealth.edu

B. M. Frye · S. Craft · J. N. Justice · S. B. Kritchevsky

Sticht Center for Healthy Aging and Alzheimer's

Prevention, Department of Internal Medicine -

Gerontology and Geriatric Medicine, Wake Forest School

of Medicine, Winston-Salem, USA

S. Craft · T. C. Register · C. A. Shively

Wake Forest Alzheimer's Disease Research Center,

Winston-Salem, USA

M. G. Baxter

Nash Family Department of Neuroscience, IW, New York, USA
Funding This work was supported by several mechanisms, including the following: National Institutes of Health (NIH) R01HL087103 (CAS), NIH RF1AG058829 (CAS and SC), P30 AG049638 (SC), T35OD010946 (PI Kavanagh), Intramural Grant from the Department of Pathology, Wake Forest School of Medicine (CAS), Wake Forest Claude Pepper Older Americans Independence Center grant P30 AG21332 (SK), Vervet Research Colony (P40-OD010965) (MJ), and the Wake Forest Clinical and Translational Science Institute (NCATS UL1TR001420).

Publisher's note Springer Nature remains neutral with regard to jurisdictional claims in published maps and institutional affiliations. 